\title{
CRIATIVIDADE E LIDERANÇA EM ORGANIZAÇÕES DO PORTOMÍDIA: UM ESTUDO À LUZ DA SOCIOLOGIA FENOMENOLÓGICA DE ALFRED SCHUTZ
}

Kelly Maria Paz E Silva ${ }^{1}$

Henrique Muzzio ${ }^{1}$

Fernando Paiva Júnior ${ }^{1}$

${ }^{1}$ Universidade Federal de Pernambuco - UFPE 


\section{CRIATIVIDADE E LIDERANÇA EM ORGANIZAÇÕES DO PORTOMÍDIA: UM ESTUDO À LUZ DA SOCIOLOGIA FENOMENOLÓGICA DE ALFRED SCHUTZ}

Resumo: Esse estudo empírico analisa o fenômeno da liderança no contexto da criatividade. O contexto organizacional contemporâneo é permeado por condições desafiadoras que emergem de um mundo pós-fordista. Nesse ambiente, a criatividade surge como um fenômeno capaz de dotar os indivíduos e as organizações de condições para conviver com essa realidade. Adicionalmente, o líder emerge como um componente central nesse cenário em que ele permite o desenvolvimento de seus seguidores com ênfase na criatividade e sua condição transformadora, como enfatiza o modelo de liderança criativa (MLC) de Rickards e Moger (2000). Baseada nas concepções fenomenológicas de Alfred Schutz, realizou-se uma pesquisa em uma incubadora de empresas do setor da economia criativa. $\mathrm{O}$ estudo evidencia que os líderes se veem como membros da equipe que têm o papel de estimular o processo criativo, ao invés de gerar imposições e regras, que poderiam restringir a capacidade criativa.

Palavras-chave: Criatividade. Liderança criativa. Economia criativa. Fenomenologia sociológica.

\section{Introdução}

O objetivo desse artigo é analisar como gestores vivenciam a liderança com ênfase na experiência em organizações incubadas no Portomídia em Recife (PE) sob à luz da sociologia fenomenológica de Alfred Schutz. Esse prisma de observação destaca que, embora o fenômeno da liderança seja um campo de pesquisa robusto na área de estudos organizacionais, especificamente no contexto da criatividade, ainda há uma carência de compreensão. Ainda mais, com a utilização da perspectiva fenomenológica, dada sua condição de compreender o fenômeno com ênfase naquele que o vivencia, possibilitando a análise de fatos e de experiências com foco em uma realidade. A pertinência desse estudo no momento atual se evidencia em função da emergência da criatividade como um fenômeno de interesse para acadêmicos, gestores e definidores de políticas públicas, que teriam uma oportunidade de ampliação dos impactos econômicos e sociais das atividades produtivas.

No cenário atual, as organizações pós-industriais precisam se adaptar constantemente às mudanças que ocorrem em nível social, cultural, econômico e político, ocasionadas pelo contexto sócio histórico no qual as mesmas estão inseridas. Porém, esse cenário contemporâneo acaba por impor dificuldades e desafios, dado que as organizações precisam se adaptar às transformações sociais na busca de garantir sua resiliência. Essa transformação se manifesta, dentre outros, pela valorização da criatividade como um fenômeno capaz de tornar indivíduos e organizações mais adaptados a esse ambiente fluido e efêmero.

Nesse contexto permeado pela criatividade emerge uma nova configuração econômica, conhecida como economia criativa. Quanto a esta, Reis (2008, p. 9) sugere que existem três pilares essenciais ao entendimento do seu lócus de atuação: "uma produção que valoriza singularidade, o simbólico e aquilo que é intangível: a criatividade". Interpreta-se aqui a criatividade como fenômeno de cunho complexo, multinível e emergente que exige uma

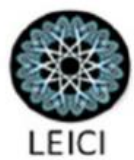


liderança capaz, com o objetivo de maximizar os benefícios das novas formas de trabalho (ANDERSON; POTOCNIK; ZHOU, 2014).

Diante das características do mercado da economia criativa, da relevância da criatividade e da inovação para suprir demandas de bens e serviços que não são produzidos em massa, ou ainda, da condição dos bens ou serviços que possuem um alto grau de trabalho analítico e criativo, o modelo gerencial dessas organizações não deveria ser guiado por pressupostos de uma economia tradicional fordista (MUZZIO; PAIVA JÚNIOR, 2015). A partir dessas considerações, é possível demonstrar a pertinência de um modelo de gestão que englobe as características multifacetadas da economia criativa. Principalmente, porque os empreendedores criativos precisam enfrentar desafios que vão além da prática criativa e envolve encontrar um mercado adequado ao seu tipo de negócio, atrair pessoas capazes, identificar recursos financeiros e técnicos e pensar estratégias competitivas (BUJOR; AVASILCAI, 2016).

Um pilar fundamental da gestão é a figura do líder, capaz de estabelecer caminhos e inspirar liderados em busca de um objetivo coletivo. Para esse cenário emergente da criatividade, a figura do líder permanece importante, porém, com necessidades de adaptação em função das características que permeiam o segmento criativo. Inclusive, sendo possível os estudos que associem o empreendedorismo com a liderança, segundo Gimenez, Ferreira e Ramos (2007). Inclusive, estes autores utilizam como um dos modelos de análise, a liderança criativa de Rickards e Moger (2000), pela qual o líder criativo permite o desenvolvimento de seus seguidores com ênfase na criatividade e sua condição transformadora.

Partindo-se do papel primordial do líder para a efetivação de uma gestão criativa, buscou-se elementos empíricos que elucidassem o modo como o gestor vivencia a liderança em organizações da economia criativa. Sendo assim, utilizou-se como objeto empírico deste estudo um espaço significativo de agregação de organizações atuantes no segmento criativo em que o sujeito epistemológico foi a figura do gestor. Destacasse que, este sujeito epistemológico seria o empreendedor dos negócios, que desenvolve os projetos das startups destinados à incubação e que posteriormente são transformados em negócios relevantes ao contexto da economia criativa. Portanto, empreendedor aqui é reconhecido como um líder de perfil criativo e inovador.

Tal estudo foi baseado na seguinte problemática: Como o gestor vivencia a liderança em organizações com experiência de incubação no Portomídia em Recife - PE sob à luz da sociologia fenomenológica de Alfred Schutz? Os resultados mostram que os líderes se veem como membros da equipe que têm o poder de estimular o processo criativo e não gerar imposições e regras, que podem acabar por diluir a capacidade criativa.

\section{O fenômeno criativo: novos caminhos}

Esta seção apresenta os conceitos básicos que permitirão compreender o grande contexto da criatividade com a discussão sobre criatividade e inovação, agregando as terminologias economia criativa (EC), gestão criativa (GC) e liderança criativa (LC).

\subsection{Criatividade e Inovação}

A criatividade pode ser percebida por meio de vários níveis de atuação, como individual, organizacional e social. Amabile (1988) considera que ela pode estar relacionada à pessoa, ao

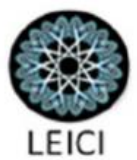


processo ou ao produto. O nível pessoal foca em indivíduos que possuem determinados traços intelectuais e de personalidade, que quando em estado de liberdade, passam uma boa quantidade de tempo, dedicados ao processo criativo. Ao passo que no nível de processo, consiste na emergência em agir para criar um novo produto singular. E por fim, no nível de produto, Amabile (1988, p. 126) considera que a "criatividade é a produção de ideias novas e úteis por um indivíduo ou grupos pequenos de indivíduos trabalhando juntos". Algo concernente com a ideia de organização, que reúne pessoas em torno do alcance de objetivos determinados.

Em relação aos fatores que influenciam na criatividade, Amabile (1997) considera que há muitas evidências que indicam que as pessoas tendem a ser mais criativas quando elas são inicialmente motivadas de maneira intrínseca ao invés de extrínseca. Ou seja, ela considera que para se manter a criatividade no nível organizacional é necessário que se preserve a motivação intrínseca na criatividade individual.

De acordo com Parjanen (2012), a criatividade também acontece no nível coletivo, à medida que as interações sociais desencadeiam novas descobertas de analogias distantes que as pessoas não teriam gerado se pensassem sozinhas. Mas a criatividade também ocorre no nível social. Isto porque, de acordo com Chedli (2014), o profissional está inserido num contexto coletivo e sua capacidade criativa sofre influência desse sistema grupal. E, conforme Muzzio (2017), o resultado dessa criatividade pode se concretizar em um produto, um serviço ou um processo organizacional que trará consequências coletivas e, com impacto positivo na EFICIÊNCIA. Porém, não se pode falar em criatividade sem levar em consideração sua implementação, que ocorre através da inovação. Como diz Amabile (1988, p. 126): "Inovação organizacional é a implementação bem sucedida de ideias criativas dentro de uma organização". Além disso, Bowen, Rostami e Steel (2010) consideram que a inovação organizacional pode direcionar ao desenvolvimento de recursos estratégicos peculiares, gerando vantagem competitiva e desempenho superior, que pode ser reutilizado em inovação e manter assim, uma vantagem considerável. Tais implicações evidenciam assim a pertinência da criatividade para a longevidade organizacional.

\subsection{Economia criativa}

A economia criativa ganhou popularidade a partir da publicação da obra Creative economy: how people make money from ideas de John Howkins, no ano de 2001. Em relação a esta modalidade de economia, o relatório da UNCTAD (2010) oferece um panorama geral e considera que a economia criativa seria um conceito em evolução baseado em ativos criativos que geram crescimento e desenvolvimento econômico, ao poder estimular a renda, possibilitar inclusão social, diversidade cultural e desenvolvimento social. Além disso, engloba aspectos econômicos, culturais e sociais que se articulam com objetivos de tecnologia, propriedade intelectual e turismo. Tratando-se de uma opção de desenvolvimento viável e que tem as indústrias criativas como centro de sua atuação.

Segundo Howkins (2001), são quinze os setores nos quais podemos agregar a criatividade: Pesquisa e Desenvolvimento (P\&D), Mercado Editorial, Software, TV e Rádio, Design, Música, Filmes, Brinquedos e jogos, Propaganda, Arquitetura, Artes Performáticas, Artesanato, Vídeo Games, Moda e Arte. De toda forma, a criatividade não pode ser entendida como exclusiva de tais atividades, pois a mesma pode se manifestar em distintas organizações, ainda mais com a ação decisiva de suas lideranças.

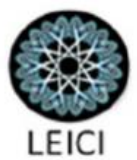




\subsection{Gestão criativa}

A gestão criativa deve articular os principais elementos que permeiam a criatividade em organizações da chamada EC. Quanto a isso, Muzzio (2017) trabalha a gestão criativa baseada na articulação de três elementos centrais que se desenvolvem no contexto da inovação organizacional. Sendo eles: o indivíduo, a liderança e a cultura.

O indivíduo criativo é aquele profissional que dotado de competências, é capaz de incitar o desenvolvimento do processo inovador nas organizações e em suas imediações por meio da operacionalização de projetos que permitem a efetivação da criatividade. Trata-se de um indivíduo chave para que o processo de criatividade seja realizado nas organizações e consequentemente, para que haja um fortalecimento da GC.

Em relação à cultura, Coelho (2010) considera que uma cultura aberta ao compartilhamento e a transparência aumentam as chances de que uma organização se torne criativa. Além disso, para o mesmo autor $(2010$, p. 83): "Só com uma cultura criativa é que a organização estará se recriando e desenvolvendo sua capacidade de dar novas significações ao mundo externo e interno". Isto porque, à medida que uma cultura organizacional é flexível, ela permite que o indivíduo realize suas atividades de forma mais livre e desta forma, para obter reconhecimento em suas ações, ele irá se esforçar mais na produção de artefatos criativos e inovadores.

A liderança, por sua vez, apresenta quatro comportamentos típicos de acordo com Bass (1999): influência idealizada, motivação inspiradora, estimulação intelectual e consideração individualizada. Enquanto Podsakoff et al. (1990) sugere a existência de seis dimensões da liderança transformacional: prover um modelo/exemplo apropriado, articular uma visão, estimular intelectualmente, prover suporte individualizado, incentivar a aceitação de metas do grupo e esperar uma alta performance. Desta forma, o líder transformacional funciona como um indivíduo chave para articular os elementos da GC, à medida que este consegue incutir nos indivíduos a necessidade de trabalhar de forma criativa e inovadora.

Mais recentemente, foi surgida uma nova perspectiva em liderança, que vai além do que propõe a liderança transformacional, a liderança criativa, pela qual é dada importância ao trabalho em equipe, mais especificamente, ao da equipe criativa para o desenvolvimento de soluções criativas e inovadoras, tanto nos processos quanto nos resultados gerados pelas organizações da EC.

\subsection{Liderança criativa}

A perspectiva sobre a liderança criativa foi proposta por Rickards e Moger (2000) e se fundamenta na utilização do modelo de Tuckman (1965) sobre o desenvolvimento do trabalho em equipe e na sua revisão (TUCKMAN; JENSEN, 1977). Ao estudarem este modelo, Rickards e Moger (2000) perceberam barreiras que são inerentes ao mesmo e que alteravam o andamento das equipes de trabalho. A primeira barreira representa as forças interpessoais e intrapessoais que precisam ser superadas frente à formação e normalização, sendo uma barreira fraca. Ao passo que a segunda barreira é mais difícil de ser enfrentada pelas equipes, já que representa as forças que são quebradas quando uma equipe supera as expectativas convencionais.

Ao observarem estas barreiras para a formação e performance das equipes, Rickards e Moger (2000) acreditavam que o desempenho da equipe e as contribuições da liderança criativa

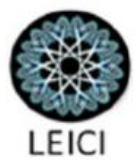


voltadas para a formação de "estruturas benignas" estavam relacionadas com o desempenho de fatores de equipes, conhecidos como: plataforma de entendimento, visão compartilhada, clima, resiliência, ideias próprias, ativação em rede e aprendizado vindo da experiência.

Em relação à plataforma de entendimento, os membros da equipe compartilham conhecimentos, crenças, valores e convicções. Enquanto na visão compartilhada, os membros compartilham um senso de propósito que orienta o progresso da equipe. No fator clima, por sua vez, o líder destaca o valor corporativo de um clima organizacional positivo e marcado pela confiança. Na resiliência, o líder busca incentivar a procura por soluções alternativas, que possam resolver expectativas frustradas.

Paralelamente, o fator ideias próprias, conta com a ação do líder para estimular a equipe a construir ideias. Ao passo que, no fator ativação em rede, há um incentivo ao estabelecimento de network com pessoas de fora da equipe, a fim de capturar habilidades, conhecimentos e recursos. E por fim, no aprendizado vindo da experiência, o líder estimula o aprendizado através da experiência dos indivíduos e a busca de soluções de maneira criativa.

\section{Em direção à sociologia fenomenológica de Schutz}

Apresenta-se inicialmente uma resumida perspectiva da sociologia fenomenológica de Alfred Schutz em função de sua aplicação empírica nesse estudo, para em seguida, apresentar a trilha metodológica desenvolvida.

\subsection{A sociologia fenomenológica de Schutz}

A sociologia fenomenológica de Alfred Schutz valeu-se da obra fenomenológica de Husserl com o objetivo de aprofundar a sociologia da compreensão desenvolvida por Max Weber, no sentido de preencher as lacunas das considerações destes.

Um termo seminal na sociologia fenomenológica é a experiência. Tanto a experiência relativa ao próprio indivíduo, como à que se aplica aos outros indivíduos presentes no mundo da vida. Schutz (1979) considera que apenas quando uma experiência é vista em retrospectiva, é que a mesma pode ser chamada de significativa. $\mathrm{O}$ autor também defende que o mundo social ou da vida é intersubjetivo, ou seja, comum a todos os seres humanos. E nesse mundo, o homem se relaciona e atribui significado a sua ação. A ação no cotidiano é estabelecida como ação social quando o indivíduo a encaminha para outras pessoas, as quais ele percebe como seres conscientes.

Schutz (1979) considera que as experiências de significado subjetivo que surgem da vida dos indivíduos podem ser chamadas de conduta. E a conduta que se baseia em um projeto, será chamada de ação. E quando essa ação é concretizada no mundo exterior, passa a ser chamada trabalho. Dessa forma, a conduta pode evoluir de uma experiência subjetiva para outra totalmente objetiva, que realiza alterações no estado do mundo exterior.

$\mathrm{E}$ as ações sociais não correspondem a um comportamento qualquer, pois elas recebem determinada motivação para que possam ser concretizadas. Schutz (1979) fala em dois tipos de motivos: "motivo a fim de" e "motivo por que". O primeiro refere-se ao futuro e o segundo remete a experiências passadas. Dessa forma, o "motivo a fim de" é algo subjetivo, pois está na mente do indivíduo e só será concretizado se o mesmo decidir traduzi-lo em trabalho. E, por sua vez, o "motivo por que" é algo objetivo, pois o indivíduo age de acordo com o que ele já viveu, ou seja, de acordo com sua história.

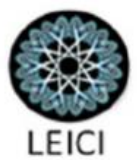


E é nesse mundo da vida que também se estabelecem as relações sociais interativas. Em relação a isto, quando outro indivíduo está ao alcance direto da experiência, em termos de tempo e espaço, evidencia-se uma situação "face a face". Essa situação, segundo Schutz (1979), exige uma simultaneidade de cada uma das consciências. Ela é a primeira e talvez uma das relações primordiais no mundo intersubjetivo. Essa condição face a face constitui um tipo de relacionamento ou de orientação, o do "Nós puro".

Em síntese, Schutz pretendia com sua sociologia fenomenológica capturar os princípios essenciais do mundo da vida, das experiências cotidianas e das relações sociais interativas. Como também buscava realizar o tratamento fenomenológico das ciências sociais, de modo a compreender a sociologia tal como ela é, suspensa de todas as crenças e pressuposições.

\subsection{Operacionalização metodológica}

A coleta de evidências se deu pelo uso de entrevistas, que são apontadas como instrumento prioritário na realização do estudo fenomenológico (MOREIRA, 2004; MEDEIROS; PASSADOR; BECHELENI, 2011).

Quanto aos critérios de inserção do sujeito, o estudo empírico foi realizado com empreendedores de organizações com experiência de incubação no programa promovido pelo Portomídia na cidade de Recife - PE. Entrevistá-los é uma forma viável para captar as experiências dos mesmos, enquanto líderes. Obtendo assim, um repertório de experiência que constituirá a forma como o empreendedor vivencia sua liderança em organizações consideradas criativas.

E, ao investigar organizações que se encontram no processo de incubação, o pesquisador pode visualizar as contribuições prestadas pelo Portomídia ao desenvolvimento do empreendimento. Ao passo que estudar antigas incubadas, permite visualizar a efetividade do programa ao sucesso da organização criativa.

Quanto aos procedimentos de análise das evidências, a análise seguiu a proposta de Sanders (1982), que estabelece a existência de três fases para a estrutura fenomenológica da pesquisa, quais sejam: Descrição do fenômeno tal como ele é apresentado pelo sujeito; Identificação dos temas relevantes que surgem a partir das falas dos sujeitos; e Agrupamento dos temas em unidades de significado ou sentido, que representarão a estrutura de significado do fenômeno. Sendo relevante considerar que o processo de redução fenomenológica permeia todo o estudo. Neste artigo, seguiu-se a proposta de redução idealizada por Paiva Júnior (2004), por representar uma forma consistente e aplicável de realizar a redução fenomenológica e eidética.

Primeiro, foi realizada uma leitura da entrevista transcrita de cada sujeito e posteriormente, procedeu-se com uma leitura mais acurada, a fim de obter as unidades de significado correspondentes. Foram obtidas 244 unidades de significado e as mesmas foram dispostas por meio de um parêntese, pelo qual o primeiro numeral corresponde ao sujeito entrevistado e o segundo numeral refere-se à unidade de significado oriunda de seu discurso e organizada em ordem sequencial.

As unidades de significado foram distribuídas em um quadro, que também conta com a coluna de compreensão do pesquisador e a coluna de relevâncias ou sínteses estruturais do fenômeno. E, à medida que foram inferidas as relevâncias relativas às unidades de significado de cada sujeito, seguiu-se com a compreensão acerca da percepção coletiva sobre o fenômeno

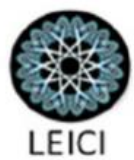


da liderança no processo de criatividade organizacional. A partir das relevâncias obtidas na fala de cada sujeito, também foram gerados "mega-temas", que consistem em grandes temas concernentes à realidade do entrevistado e articulados com as teorias do estudo.

Em seguida, a partir dos 321 temas emergentes das unidades de significado dos sujeitos, foi feita a redução eidética, pela qual os mesmos foram reduzidos a temas que contém as categorias de tipicidades ou relevâncias. Procedeu-se, então, com as reduções, até se obter um número relativamente menor com 23 temas, distribuídos entre 5 categorias universalizantes (Quadro 1). Finalizando assim, o tratamento das evidências.

Quadro 1: Quadro de categorias universalizantes

\begin{tabular}{|c|l|}
\hline Categorias universais & \multicolumn{1}{c|}{ Temas } \\
\hline Criatividade e Inovação & Criatividade em vários níveis \\
& Inovação em vários níveis \\
& Interligação entre criatividade e inovação \\
& Fatores de estímulo à criatividade e inovação \\
\hline Economia criativa & Valorização da criatividade e da singularidade \\
& Setores criativos \\
& Geração de bens e serviços criativos \\
& Crescimento econômico \\
& Contexto tecnológico \\
& Portomídia: fomento e necessidade de mudança \\
\hline Gestão organizacional & Gestão flexível, compartilhada e criativa \\
& Competências e capacidades do indivíduo criativo \\
& Seleção de perfis humanos agregadores \\
& Cultura horizontal, colaborativa e flexível \\
& Cultura em construção e cultura criativa \\
\hline Liderança organizacional & Liderança transformacional \\
& Liderança participativa e criativa \\
\hline Equipe criativa & Plataforma de entendimento \\
& Visão compartilhada \\
& Clima \\
& Resiliência \\
& Ideias próprias \\
& Ativação em rede e aprendizado vindo da experiência \\
\hline
\end{tabular}

Fonte: Os autores (2018)

Esse quadro construído a partir das reduções fenomenológicas, permeará as discussões da próxima sessão deste estudo.

\section{Compreendendo o fenômeno criativo}

$\mathrm{O}$ ambiente e as experiências vivenciadas pelos indivíduos, podem influenciar a criatividade e a inovação. Sendo assim, percebem-se vários meios de estímulo, mas independentemente de quais sejam, o líder precisa identificar os que serão adequados à sua equipe e que portanto, possibilitarão o comprometimento com o pensamento criativo e a prática inovadora, resultando em consequências benéficas para a organização.

\subsection{Criatividade e inovação}


A criatividade e a inovação são elementos essenciais para a formação e o desenvolvimento de empreendimentos criativos e as percepções sobre os mesmos, variam entre os sujeitos entrevistados. Por exemplo, um dos empreendedores considerou que a criatividade pode ser vista como algo processual na qual é premente desenvolver ideias que gerem produtos singulares (1.2). Este posicionamento se adéqua ao que Amabile (1988) considera como criatividade no nível de processo.

Paralelamente, outros sujeitos consideram a criatividade a nível de produto, como aquela direcionada à criação de coisas novas, singulares e úteis $(1.2 ; 2.1)$. Consiste no que Amabile (1988) argumentou como criatividade no nível de produto. Dessa forma, o líder e sua equipe buscam direcionar o pensamento e a criatividade no desenvolvimento de um trabalho que possa resultar em bens e serviços satisfatórios ao mercado e à organização.

Em relação ao termo inovação, o empreendedor considera que ela pode ser disruptiva ou incremental $(1.1 ; 7.1)$. Sendo a primeira, algo mais radical que impõe mudanças nos métodos de trabalho e na concepção dos bens e serviços. Enquanto a segunda vem como uma forma de incrementar o que já existe, gerando um aperfeiçoamento. Esta última condiz com o que Bowen, Rostami e Steel (2010) consideram como inovação organizacional, que é incrementar ou aperfeiçoar determinado processo ou produto.

Além disso, a inovação se relaciona ao que Schutz (1979) chama de ação, que seria a conduta baseada em um projeto (de aperfeiçoamento). E como ela trabalha para o alcance de objetivos específicos, como o aperfeiçoamento dos processos e produtos, ela se configura como um "motivo a fim de" (SCHUTZ, 1979), que se concretiza através do trabalho (SCHUTZ, 1979), que é a geração de produtos (bens e serviços) inovadores. Porém, no contexto atual, a criatividade acontece atrelada à inovação, porque ambas permitem a obtenção de resultados satisfatórios e diferenciados para o mercado. Isto porque a criatividade constitui a geração de novas ideias $(1.2 ; 2.1 ; 8.1 ; 9.1 ; 11.1 ; 12.1)$ e a inovação realiza a implementação dessas, através dos métodos de trabalho e dos produtos destinados ao mercado $(2.1 ; 3.1 ; 4.1 ; 5.1 ; 6.3 ; 7.3 ; 8.1$; $9.2 ; 9.13 ; 12.2)$. Nesse contexto, a criatividade se associa ao que Schutz (1979) chama de conduta, a inovação à ação e os produtos criativos e inovadores ao resultado do trabalho.

A criatividade pode ter também motivação intrínseca ou extrínseca $(6.2 ; 10.1 ; 12.7)$. No primeiro caso, a criatividade seria algo inato ao ser humano e dependente de estímulos constantes para manter a motivação interna. Quanto a isso, Amabile (1997) considera que para manter a criatividade no nível organizacional é necessário que se preserve a motivação intrínseca na criatividade individual. Enquanto no segundo caso, a criatividade seria algo a ser desenvolvido através de elementos exteriores, ou seja, por meio de motivação extrínseca. Tratase de uma ideia questionável, à medida que a criatividade depende inicialmente do ser humano para a geração de ideias e, conforme Amabile (1997), há evidências que indicam que as pessoas tendem a ser mais criativas quando elas são inicialmente motivadas de maneira intrínseca ao invés de extrínseca.

\subsection{Economia criativa}

A EC ainda é um conceito em formação na mente das pessoas e marcado por certa singularidade. Dessa forma, buscou-se realizar interação entre a percepção dos empreendedores analisados e os insights dos estudiosos presentes na literatura sobre economia criativa e seus

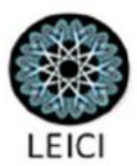


elementos de interface com a prática empreendedora (OLIVEIRA; MELO, 2018; QUEIROZ; PARADELA, 2017).

Alguns sujeitos consideram que a produção com criatividade e a geração de singularidade são valorizadas na economia criativa $(1.4 ; 3.2 ; 5.3 ; 8.21 ; 9.4 ; 11.4)$. Isto caracteriza o cerne da EC: produzir de forma diferenciada e inovadora, através da criatividade e, se alinha ao que Reis (2008) considera como pilares essenciais ao entendimento do lócus de atuação da EC, que são: "uma produção que valoriza singularidade, o simbólico e aquilo que é intangível: a criatividade".

Como também, o gestor acredita que a produção na economia criativa visa atender nichos específicos de consumo $(1.4 ; 5.3 ; 9.4)$. Ou seja, a produção na EC é pautada numa maior personalização dos bens e serviços, com vistas a atender os desejos de clientes específicos, distanciando-se assim de uma produção em massa.

Há também o pensamento sobre a EC que se orienta para a existência de "setores criativos". Neste caso, o empreendedor considera que a economia criativa é formada por setores criativos $(2.4 ; 3.4 ; 3.5 ; 4.3 ; 5.4 ; 5.5 ; 6.5 ; 8.5 ; 12.5)$. Apesar de ser uma visão meramente classificatória da EC, a divisão em setores criativos contribui para a disseminação do termo e o direcionamento das ações de fomento, como políticas públicas de incentivo à inovação. $\mathrm{O}$ Portomídia é um exemplo disso, ao delimitar suas áreas de atuação. E como essa classificação visa facilitar o entendimento da EC e o direcionamento de suas ações, ela pode ser vista como um "motivo a fim de", conforme pensado por Schutz (1979).

Portanto, a EC parte dessa dinâmica de geração de bens e serviços criativos que preza pelo uso da criatividade e da inovação em alguma fase ou várias fases de seu processo. Além disso, em alguns momentos evidencia-se que a EC se encontra atrelada ao crescimento econômico. Quanto a isto, alguns gestores consideram que a economia criativa promove a geração de renda e o crescimento econômico $(2.4 ; 3.4 ; 3.5 ; 4.3 ; 5.4 ; 5.5 ; 6.5 ; 7.3 ; 8.5 ; 10.3$; $10.3 ; 12.5)$. Ou seja, a EC consegue transformar a criatividade em algo economicamente viável. Conforme o próprio conceito de EC da UNCTAD (2010): a EC pode estimular a geração de renda, a criação de empregos e a exportação de ganhos, ao mesmo tempo que gera inclusão social, diversidade cultural e desenvolvimento humano. Porém, os empreendedores não levaram em consideração a possibilidade que a EC tem de gerar desenvolvimento econômico, ou seja, o crescimento econômico aliado a melhoria da qualidade de vida das pessoas e do próprio ambiente. Além disso, os protagonistas da economia criativa presentes na era digital precisam estar conectados com o contexto tecnológico atual $(5.8 ; 6.9 ; 8.9 ; 9.5 ; 12.5 ; 12.6)$. Quanto a esse posicionamento, o próprio conceito de EC desenvolvido pela UNCTAD (2010), considera que ela abraça aspectos econômicos, culturais e sociais que interagem com objetivos de tecnologia, propriedade intelectual e turismo.

E por fim, nesta categoria universalizante, também emerge a relação entre a EC e o lócus de estudo - o Portomídia. Grande parte dos sujeitos consideram que o Portomídia constitui um órgão de apoio e fomento à economia criativa $(1.5 ; 3.6 ; 4.4 ; 5.5 ; 6.8 ; 7.5 ; 11.5 ; 12.4 ; 12.6)$. Conforme o Porto Digital (2017), a iniciativa objetiva transformar a cidade de Recife - PE no principal polo de suporte tecnológico e direcionado a apoiar a estruturação de seis áreas de negócios sustentáveis e pertencentes à EC: games, cinema, multimídia, design, fotografia e música. Porém, esse posicionamento se insere mais no plano ideal do que no real, à medida que algumas áreas receberam mais atenção e outras foram deixadas de lado, como games.

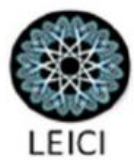


Os gestores criativos consideram que os pilares educação e empreendedorismo contribuem para o desenvolvimento dos negócios tecnológicos, a exemplo dos empreendimentos incubados $(1.20 ; 2.5 ; 3.6 ; 7.4 ; 10.4 ; 11.5 ; 12.17)$. De acordo com o Porto Digital (2017), o pilar educação contribui com a capacitação dos profissionais, ao oferecer cursos e eventos de qualificação e o pilar empreendedorismo funciona como uma incubadora de negócios. Esses pilares são, portanto, a base para todas as etapas do processo de incubação. Enquanto os outros pilares - experimentação e exibição - não são citados pelos empreendedores, o que pode significar que eles são negligenciados ou recebem menor importância do que os de educação e empreendedorismo.

Alguns sujeitos consideram que o Portomídia necessita de uma mudança estratégica $(6.9 ; 12.6)$. Essa transformação deve abarcar uma campanha de marketing eficiente, que possa mostrar a importância do Portomídia para a EC do estado. Assim como, devem ser direcionadas as ações para que todas as áreas sejam contempladas com os benefícios da incubação e, dessa forma, haja geração de aprendizado e resultados significativos tanto para as startups quanto para a EC como um todo.

\subsection{Gestão organizacional}

A gestão organizacional ainda é um conceito em formação na mente dos gestores, então eles podem apresentar inúmeros posicionamentos em relação as suas características e o modo como ela pode ser configurada.

A gestão na economia criativa é flexível em termos de processos e hierarquia $(1.12 ; 2.9$; $7.10 ; 10.11 ; 11.10 ; 12.9)$. Seria então, uma gestão que busca se adequar às características multifacetadas de uma equipe formada por indivíduos criativos e que necessitam de maior liberdade para exercer sua capacidade criativa. E conforme Muzzio e Paiva Júnior (2015) argumentam, em virtude das próprias características do mercado da EC, o modelo gerencial dessas organizações não deveria ser guiado por pressupostos de uma economia tradicional fordista.

Há também a percepção de que a gestão é compartilhada, possibilitando a satisfação da equipe $(7.10 ; 8.13)$. A participação da equipe não se restringe à execução do processo criativo e se estende à gestão no negócio por intermédio do estímulo do líder e da abertura propiciada pelo ambiente de trabalho. Este posicionamento pode ser comparado ao que Rickards e Moger (2000) consideram como o fator de desenvolvimento de equipe - Visão compartilhada.

Determinados empreendedores consideram que a gestão se torna criativa pelo perfil criativo da equipe e pelo modelo de atuação da empresa $(7.19 ; 11.10 ; 5.9 ; 1.12)$. Ou seja, os elementos que compõem a organização como os indivíduos e o modelo de negócio, são permeados pela criatividade. Então, se adequaria ao que Muzzio (2017) considera como um dos elementos da GC - o indivíduo criativo, que é capaz de incitar o desenvolvimento do processo inovador nas organizações e em suas imediações por meio da operacionalização de projetos que permitem a efetivação da criatividade. Em sendo assim, ainda não há uma concepção clara do que seria uma GC por parte dos gestores, até pela tendência a se desconsiderar alguns aspectos primordiais dessa modalidade de gestão, como a cultura criativa e a liderança transformacional. Porém, isso acontece apenas quando os sujeitos são indagados sobre o que seria uma GC. Em outros momentos, quando falam sobre o indivíduo criativo e a liderança, eles conseguem reconhecer sua importância para o andamento das organizações criativas.

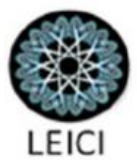


Em relação a um dos elementos da gestão criativa - o indivíduo criativo - alguns empreendedores consideram que ele é dotado de competências para a resolução de problemas $(1.6 ; 3.7 ; 4.15 ; 9.14)$. Dessa forma, o indivíduo criativo utiliza a criatividade para desenvolver soluções para problemas que surgem no desenvolvimento do trabalho e contribui para que a organização se diferencie no mercado, à medida que dentro de sua equipe existe o estoque de conhecimento necessário para lidar com as situações inesperadas. E esse estoque pode ser visto como o que Schutz (1979) chama de ready-made de um grupo, que seria um "pensar como sempre" e com aspectos subjetivos, inteligíveis apenas por quem faz parte do mesmo.

O indivíduo criativo possui a capacidade de criar bens e serviços novos ou transformar os que já existem no mercado $(2.6 ; 4.6 ; 5.6 ; 7.6 ; 8.8 ; 9.7 ; 11.6 ; 12.7)$. Isto quer dizer que ele é um sujeito crucial no processo de criatividade, à medida que desenvolve ideias novas e úteis e consegue incrementar as que já existem, gerando bens e serviços inovadores. E quando os gestores reconhecem a importância das capacidades destes, eles estão demonstrando o quanto os indivíduos criativos podem ser relevantes também para a formação de uma GC.

Atrelada à discussão sobre o indivíduo criativo, alguns sujeitos acreditam que o foco da seleção deve ser em candidatos com perfil criativo, analítico e que se alinhem com a cultura organizacional $(1.8 ; 2.7 ; 3.8 ; 4.7 ; 5.1 ; 6.11 ; 6.12 ; 7.7 ; 9.8 ; 10.7 ; 11.7 ; 11.8)$. Ou seja, busca-se um perfil que contribua com o desenvolvimento de uma equipe criativa e que venha a fortalecer a cultura organizacional. Inclusive o perfil analítico é um fator que contribui para a "resiliência" (RICKARDS; MOGER, 2000) da equipe criativa.

$\mathrm{Na}$ seleção, busca-se pessoas com características agregadoras e que contribuam para o processo criativo $(5.7 ; 5.13 ; 6.12 ; 8.10 ; 9.8 ; 9.14 ; 10.6 ; 10.17)$. Essas características seriam aquelas que podem trazer algo de novo às organizações, como: talento, proatividade, comprometimento, compreensão, atenção às inovações tecnológicas, abertura à crítica, disposição a aprender e amor pelo trabalho.

Em relação a outro elemento que permeia a gestão organizacional - a cultura - alguns empreendedores consideram que a cultura organizacional é horizontal e colaborativa $(1.9 ; 1.10$; $3.9 ; 6.13 ; 7.8 ; 11.9)$. Uma cultura organizacional marcada pela horizontalidade caracterizaria uma cultura que destaca o compartilhamento de conhecimentos, informações e experiências por parte da equipe de trabalho. E de acordo com Coelho (2010), uma cultura aberta ao compartilhamento e a transparência aumenta as chances de que uma organização se torne criativa.

Outros sujeitos consideram que a cultura é flexível $(1.10 ; 6.13 ; 11.9)$. Uma cultura flexível busca se adequar às necessidades dos indivíduos criativos, que fazem parte de sua equipe e isso já acontece no próprio processo de gestão de pessoas, ao conceder jornadas de trabalho mais flexíveis, por exemplo. Dessa forma, eles têm suas peculiaridades e necessitam de abertura para desenvolver sua capacidade criativa.

Como também, alguns empreendedores consideram que a cultura organizacional está em construção $(4.8 ; 6.13)$. Uma cultura em construção condiz com o fato de que ela ainda se encontra em estado de formação nas organizações dos gestores que a citam. Isto pode ser explicado por algumas organizações se configurarem como startups e ainda estarem se estabelecendo no mercado. Como também, por se tratar de organizações pertencentes à EC, muitos fatores de uma organização tradicional ficam passíveis a sofrerem mudanças e incrementos em virtude da inserção do aspecto criatividade como cerne desses

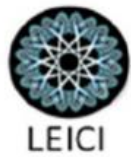


empreendimentos. Enquanto outros sujeitos consideram que a cultura é formada por valores norteadores e agregadores $(1.6 ; 2.8 ; 3.16)$. Esses valores de acordo com Muzzio e Paiva Júnior (2015) se concentram em condições que possibilitariam um contexto simbólico de criatividade. $\mathrm{Ou}$ seja, a cultura organizacional busca cultivar valores que possam auxiliar a equipe no processo criativo e que possam trazer benefícios à organização como um todo.

Os entrevistados ainda não possuem um posicionamento claro em relação à cultura criativa e, por conseguinte, sobre a cultura organizacional das empresas. Isto talvez possa ser explicado pelas características dos indivíduos que formam a equipe, que são mais concentrados no processo de criatividade e se distanciam dos fatores de uma administração tradicional.

\subsection{Liderança transformacional}

A liderança assume um papel importante nos empreendimentos da EC, à medida que contribui para o desenvolvimento da equipe criativa e consequentemente, para o uso da criatividade e da inovação nos processos organizacionais. E percebeu-se no estudo, várias associações do posicionamento dos entrevistados com as dimensões e comportamentos que caracterizam a liderança transformacional.

Quanto às dimensões da liderança transformacional, alguns gestores consideram que a liderança exige alta performance de produção da equipe $(3.12 ; 3.17)$, o que condiz com o que Podsakoff et al. (1990) considera como alta performance. Enquanto, outros entrevistados pensam na possibilidade de geração de aprendizado e o investimento no mesmo $(2.1 ; 3.20 ; 5.17$; $6.24 ; 6.27 ; 9.17 ; 11.11 ; 11.19 ; 12.18)$, o que concerne ao que Podsakoff et al. (1990) considera como "Estimular intelectualmente". E ainda, um dos empreendedores considera que o líder consegue articular uma visão para perceber oportunidade de mercado (8.20), um posicionamento que se adequa ao que Podsakoff et al. (1990) percebe como "Articular uma visão".

Como também, em relação aos comportamentos da liderança transformacional, a visão da possibilidade de geração de aprendizado e o investimento no mesmo $(2.1 ; 3.20 ; 5.17 ; 6.24$; $6.27 ; 9.17 ; 11.11 ; 11.19 ; 12.18$ ), está associada ao que Bass (1999) considera como "estimulação intelectual". E paralelamente, existe o posicionamento de que o líder também consegue exercer influência idealizada na equipe $(8.20 ; 5.11)$, o que condiz com um comportamento citado por Bass (1999) — a influência idealizada.

Assim como, o líder criativo estimula o desenvolvimento dos fatores de equipe criativa $(1.19 ; 2.2 ; 2.11 ; 2.12 ; 2.14 ; 3.11 ; 3.18 ; 3.21 ; 4.14 ; 4.16 ; 4.17 ; 5.10 ; 5.12 ; 5.14 ; 5.18 ; 6.21 ; 6.22$; $6.23 ; 7.14 ; 7.15 ; 7.16 ; 7.17 ; 8.17 ; 8.20 ; 10.12 ; 10.16 ; 11.14 ; 12.15 ; 11.13 ; 11.17 ; 11.20 ; 12.20)$. Ou seja, ele constitui papel importante para que a equipe desenvolva os fatores de plataforma de entendimento, visão compartilhada, clima, resiliência, ideias próprias, ativação em rede e aprendizado vindo da experiência. Como Rickards e Moger (2000) defendem, a contribuição da LC para o desenvolvimento de estruturas benignas estariam fortemente relacionadas com o desempenho de fatores de equipe. E ao buscar desenvolver esses fatores de equipe, o líder tem um "motivo a fim de" (SCHUTZ, 1979), que é desenvolver as estruturas benignas. Porém, alguns fatores se sobressaem em relação a outros. Dessa forma, a LC acontece de forma parcial nas organizações estudadas, à medida que alguns fatores de desenvolvimento de equipe são supervalorizados, enquanto outros recebem menor atenção e precisariam de ajustes para que as organizações pudessem obter os melhores resultados, a partir de seu próprio capital humano.

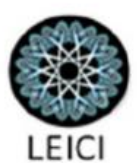




\subsection{Equipe criativa}

Os fatores de equipe são imprescindíveis para a determinação da existência de uma LC. Eles não se apresentam isoladamente e podem se complementar para possibilitar o desenvolvimento de outros fatores, como a articulação de projetos em regime de cocriação nas redes de negócio.

Em relação à plataforma de entendimento, existem várias percepções dos entrevistados que a ela se relacionam, cabendo aqui apresentar as que predominam: a cultura é colaborativa e aberta ao compartilhamento $(1.9 ; 1.10 ; 3.9 ; 6.13 ; 7.8 ; 11.9)$; o compartilhamento de conhecimentos estimula o aprendizado e progresso da equipe $(1.14 ; 3.18 ; 4.12 ; 10.19$; 11.18); e o compartilhamento de conhecimentos pela equipe pode ser verbal ou através de ferramentas como: slack, drive, wiki, ready mind, metodologia scrum, boards no Pinterest e redes sociais $(2.10 ; 6.16 ; 10.12 ; 10.20 ; 11.11)$. E essa plataforma de entendimento criada pela equipe pode ser vista como o ready-made de Schutz (1979). Além disso, a presença deste fator pode estimular o desenvolvimento do fator de equipe denominado "clima".

O fator visão compartilhada, por sua vez, apresenta uma forte relação com o fator anterior - a plataforma de entendimento - isto porque ele pode contribuir para que a equipe também compartilhe propósitos e metas em comum, que sejam uma fonte de estímulo ao desenvolvimento do trabalho com criatividade e inovação. Esse posicionamento pode ser visualizado através de alguns sujeitos que consideram que o compartilhamento de conhecimentos estimula o aprendizado e progresso da equipe $(1.14 ; 3.18 ; 4.12 ; 10.19 ; 11.18)$.

Em relação ao fator clima, alguns empreendedores consideram que o brainstorming de ideias ajuda a observar o mercado e tornar o ambiente propício à criatividade e ao compartilhamento de conhecimentos $(2.3 ; 7.12 ; 12.13)$. Ou seja, o brainstorming pode contribuir para o desenvolvimento de três fatores de equipe - plataforma de entendimento, visão compartilhada e clima (RICKARDS; MOGER, 2000). E esse pensamento de compartilhamento criado pela equipe pode ser visto como o ready-made citado por Schutz (1979).

O ambiente leve, colorido e descontraído contribui para a formação de um ambiente criativo $(4.13 ; 6.18 ; 10.9 ; 12.12)$. Neste caso, a configuração do ambiente físico pode influenciar no estado de espírito de equipe e consequentemente, gerar benefícios no que Rickards e Moger (2000) chamam de clima de trabalho e no próprio desenvolvimento dos bens e serviços. Sendo também significativo que o fator de equipe - resiliência - exerce influência sobre o "clima", pois conforme um dos gestores a resolução de problemas via recursos organizacionais propicia a formação de um ambiente criativo $(10.11 ; 10.13)$. Este fato, permite encaminhar as discussões para as percepções sobre o fator resiliência.

Alguns empreendedores argumentam sobre o ato de prever as situações inesperadas e formular as soluções antes que aconteçam $(6.20 ; 8.16 ; 11.14 ; 12.14)$. Isto seria como a implantação de uma gestão de risco e uma forma de melhorar a resiliência da equipe através de um processo de antecipação do risco/problema e desenvolvimento de soluções viáveis. É o que Rickards e Moger (2000) defendem para gerar flexibilidade na equipe.

Existem vários posicionamentos sobre o fator ideias próprias, porém, dois pensamentos predominaram nos relatos, um deles considera que a equipe precisa estar comprometida com o desenvolvimento do processo criativo em qualquer situação $(2.13 ; 3.16$;

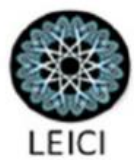


$4.16 ; 5.8 ; 9.15 ; 11.15)$. Este direcionamento de se comprometer com a construção de ideias condiz com o próprio conceito de criatividade, como a capacidade de construir coisas novas e úteis, conforme Amabile (1988).

Ao passo que o segundo pensamento aborda o papel do líder como estimulador da equipe. Conforme os sujeitos entrevistados, o líder promove liberdade para estimular a equipe na construção de ideias criativas $(2.14 ; 3.18 ; 4.17 ; 5.10 ; 6.22 ; 6.23 ; 11.17 ; 11.20)$. Ou seja, a liberdade seria uma forma de comprometer e estimular a equipe a criar quando em estado de liberdade, algo que condiz com a criatividade pessoal conceituada por Amabile (1988).

O fator "ideias próprias" é o mais citado pelos entrevistados, o que pode ser explicado pelo fato de se tratar de organizações pertencentes à EC, que em seu cerne utilizam a criatividade com uma estratégia de atuação. E os empreendedores consideram que ele pode ser estimulado de várias formas, desde o ambiente até a atuação do líder. Enquanto, os fatores de desenvolvimento de equipe "ativação de rede" e "aprendizado vindo da experiência" são os menos citados pelos sujeitos entrevistados. Isto talvez possa ser explicado pelo fato das organizações estudadas serem startups ou estarem no mercado a pouco tempo e, portanto, terem estabelecido pouco network ou não terem muitas experiências a serem compartilhada.

Em relação ao fator ativação de rede, alguns gestores consideram que a liderança estimula a formação de network para a aquisição de conhecimentos e a valorização de opiniões alheias ao projeto $(2.2 ; 6.23)$. A liderança busca estimular a equipe a estabelecer conexões com outros indivíduos ou até mesmo organizações, que possam ter conhecimentos inovadores e que venham contribuir para o processo criativo. Assim como, a equipe pode contribuir com os projetos de outras organizações. Desta forma, também propicia o fator "resiliência".

Já o fator aprendizado por experiência é percebido por alguns sujeitos que consideram que o aprendizado é vindo da experiência $(1.21 ; 2.15 ; 4.18 ; 6.24 ; 9.17)$. Sendo o líder neste processo, um elemento primordial para estimular a troca de experiências, que se desdobram em resultados benéficos para a organização. E portanto, trata-se de um fator de equipe que precisa ser melhor explorado, à medida que contribui com a resolução de problemas e o desenvolvimento do processo criativo, através dos próprios recursos organizacionais.

Não só na análise dos fatores de equipe criativa, mas também nos aspectos que caracterizam a gestão criativa, existe uma liderança que é parte integrante da equipe e que estimula os colaboradores a tomarem decisões e pensarem de forma criativa e inovadora. Desta forma, a liderança atua num espírito de colaboração que gera resultados inovadores e seriam difíceis de ser alcançados de maneira rígida e tradicional.

\section{Considerações finais}

O estudo se desenvolveu a fim de responder ao questionamento principal: Como o gestor vivencia a liderança em organizações com experiência de incubação no Portomídia em Recife - PE sob à luz da sociologia fenomenológica de Alfred Schutz?

Os resultados aqui analisados são importantes na colaboração para a consolidação de uma teoria da gestão criativa e da liderança criativa. As evidências levantadas ajudam a consolidar um campo em formação que busca compreender melhor o fenômeno da liderança no contexto criativo.

Como contribuições organizacionais, destaca-se a importância do cultivo de aspectos que propiciem uma gestão criativa e uma liderança criativa, além da necessidade de melhoria

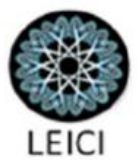


em alguns fatores de equipe criativa, como ativação de rede e o aprendizado oriundo da experiência.

Para o campo da Administração, os resultados contribuem para a consolidação de um conhecimento gerencial a ser desenvolvido e lapidado para que os líderes e suas equipes que operam em organizações dos mais diversos segmentos criativos possuam uma expertise de gestão que seja capaz de produzir resultados organizacionais mais eficientes ao reconhecer as especificidades da criatividade e liderar um processo dinâmico que estruture os líderes, os liderados e a cultura organizacional baseado na criatividade.

A preocupação gerencial do debate reside no fato de que muitas startups que entram no processo de incubação não conseguem evoluir com seus projetos criativos ou quando saem da incubação, não conseguem permanecer no mercado. E como sugestão para futuros estudos, recomenda-se pesquisas em outras modalidades de incubadoras, para que se possa avaliar como são desenvolvidos aspectos teórico-empíricos em outro contexto organizacionais e, assim, gerar comparações ou divergências.

\section{Referências}

AMABILE, T. M. A model of creativity and innovation in organizations. Research in Organizational Behavior, v. 10, p. 123-167, 1988.

Motivating Creativity in Organizations: On Doing What You Love and Loving What You Do. California Management Review, v. 40, n. 1, p. 39-58, 1997.

ANDERSON, N.; POTOCNIK, K.; ZHOU, J. Innovation and Creativity in Organizations: A State-of-the-Science Review, Prospective Commentary, and Guiding Framework. Journal of Management, v. 40, n. 5, p. 1297-1333, 2014.

BASS, B. M. Two decades of research and development in transformational leadership. European Journal of Work and Organizational Psychology, v. 8, n. 1, p. 9-32, 1999. BOWEN, F.; ROSTAMI, M.; STEEL, P. Timing is everything: A meta-analysis of the relationships between organizational performance and innovation. Journal of Business Research, n. 63, p. 1179-1185, 2010.

BUJOR, A.; AVASILCAI, S. The Creative Entrepreneur: a Framework of Analysis. Procedia Social and Behavioral Sciences, v. 221, n. 29, p. 21-28, 2016.

CHEDLI, M. K. E. Obtained Resources through Individual Networking inside the Organization, Creativity of the Supervisor and Innovation. Economics, Management, and Financial Markets, v. 9, n. 4, p. 376-394, 2014.

COELHO, D. P. Gestão criativa: em busca da sustentabilidade organizacional. Revista de Psicologia, v. 1, n. 2, p. 77-87, 2010.

GIMENEZ, F. A.; FERREIRA, J. M.; RAMOS, S. C. Entrepreneurship and creative leadership. Frontiers of Entrepreneurship Research, v. 27, n. 5, 2007.

HOWKINS, J. Creative economy: how people make money from ideas. Penguin Global, 2002 [2001].

MEDEIROS, M. L.; PASSADOR, J. L.; BECHELENI, D. G. A fenomenologia e a pesquisa em turismo: reflexões para aplicação com base no turismo gastronômico. Turismo - Visão e Ação, v. 13, n. 1, p. 20-34, 2011.

MOREIRA, D. A. O método fenomenológico na pesquisa. São Paulo: Pioneira Thomson Learning, 2004. 
MUZZIO, H. Indivíduo, Liderança e Cultura: Evidências de uma Gestão da Criatividade.

Revista de Administração Contemporânea. v. 21, n. 13, p. 107-124, 2017.

MUZZIO, H.; PAIVA JUNIOR, F. G. A pertinência de adequação da gestão criativa à identidade do indivíduo criativo. Revista Contemporânea de Economia e Gestão, v. 13, n. 3, p. 1-17, 2015.

OLIVEIRA, A. G. M.; MELO, M. C. O. L. Entrepreneurship and Creative Economy: Mental Models of Cultural Entrepreneurs in Belo Horizonte, Brazil. In: Entrepreneurship-

Development Tendencies and Empirical Approach. InTech, 2018.

PAIVA JÚNIOR, F. G. O empreendedorismo na ação de empreender: uma análise sob o enfoque da fenomenologia sociológica de Alfred Schutz. 2004. (Doutorado em

Administração) - Centro de Pós-Graduação e Pesquisas em Administração, Universidade Federal de Minas Gerais, Belo Horizonte.

PARJANEN, S. Experiencing Creativity in the Organization: From Individual Creativity to Collective Creativity. Interdisciplinary Journal of Information, Knowledge, and

Management, v. 7, p. 109-128, 2012.

PODSAKOFF, P. M. et al. Transformational leader behaviors and their effects on follower trust in leader, satisfaction, and organizational citizenship behavior. Leadership Quarterly, v. 1, p. 107-142, 1990.

PORTO DIGITAL. Portomídia. Recife, 2017. Disponível em:

http://www.portodigital.org/diferenciais/programas-e-servicos/portomidia. Acesso em: 22 abr. 2017.

QUEIROZ, A. L.; PARADELA, C. L. Empreendedorismo, indústria criativa e economia criativa: uma evolução conceitual. Revista Eletrônica Estácio Papirus, v. 4, n. 2, p. 124146, 2017.

REIS, A. C. F. Economia Criativa como estratégia de desenvolvimento: uma visão dos países em desenvolvimento. São Paulo: Itaú Cultural, 2008. 268 p. Disponível em:

http://www.isegnet.com.br/siteedit/arquivos/Economia_Criativa_Estrategias_Ana\%20Carla_I tau.pdf. Acesso em: 19 abr. 2017.

RICKARDS, T.; MOGER, S. Handbook for creative team leaders. Aldershot: Gower, 1999.

Creative leadership processes in project team development: na alternative to

Tuckman's stage model. British Journal of Management, Chichester, v. 11, n. 4, p. 273-283, 2000.

SANDERS, P. Phenomenology: a new way of viewing organizational research. Academy of Management Review, v. 7, n. 3, p. 353-360, 1982.

SCHUTZ, A. Fenomenologia e Relações Sociais. Rio de Janeiro: Zahar Editores, 1979.

TUCKMAN, B. W. Developmental sequence in small groups. Psychological Bulletin, v. 63, n. 6, p. 384-399, 1965.

TUCKMAN, B. W.; JENSEN, M. C. Stages of Small Group Development Revisited, Group and Organizational Studies, v. 2, p. 419-427, 1977.

UNCTAD - Conferência das Nações Unidas para o Comércio o Desenvolvimento \& PNUD Programa das Nações Unidas para o Desenvolvimento. Economia Criativa: Uma Opção de Desenvolvimento Viável. Nações Unidas, 2010.
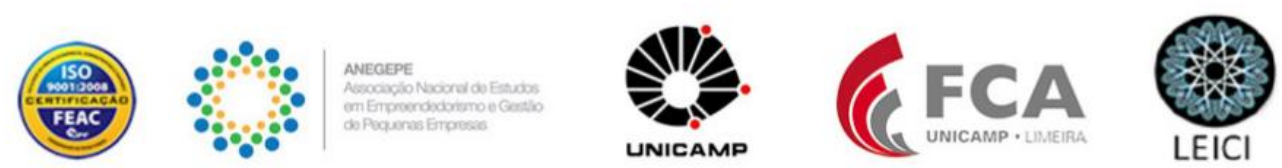